\title{
The effect of background hydrometeorological conditions on the sensitivity of evapotranspiration to model parameters: analysis with measurements from an Italian alpine catchment
}

\author{
Nicola Montaldo ${ }^{1}$, Vania Toninelli ${ }^{1}$, John D. Albertson ${ }^{2}$, Marco Mancini $^{1}$ and Peter A. Troch ${ }^{3}$ \\ ${ }^{1}$ Dipartimento di Ingegneria Idraulica, Ambientale, Infrastrutture viarie e del Rilevamento, Politecnico di Milano, Italy \\ ${ }^{2}$ Department of Civil and Environmental Engineering, Pratt School of Engineering, Duke University, Durham, NC, USA \\ ${ }^{3}$ Department of Environmental Sciences, Wageningen University, Netherlands
}

Email for corresponding author: Nicola.Montaldo@polimi.it

\begin{abstract}
Recent developments have made land-surface models (LSMs) more complex through the inclusion of more processes and controlling variables, increasing numbers of parameters and uncertainty in their estimates. To overcome these uncertainties, prior to applying a distributed LSM over the whole Toce basin (Italian Alps), a field campaign was carried out at an experimental plot within the basin before exploring the skill and parameter importance (sensitivity) using the TOPLATS model, an existing LSM. In the summer and autumn of 1999, which included both wet (atmosphere controlled) and dry (soil controlled) periods, actual evapotranspiration estimates were performed using Bowen ratio and, for a short period, eddy correlation methods. Measurements performed with the two methods are in good agreement. The calibrated LSM predicts actual evapotranspiration quite well over the whole observation period. A sensitivity analysis of the evapotranspiration to model parameters was performed through the global multivariate technique during both wet and dry periods of the campaign,. This approach studies the influence of each parameter without conditioning on certain values of the other variables. Hence, all parameters are varied simultaneously using, for instance, a uniform sampling strategy through a Monte Carlo simulation framework. The evapotranspiration is highly sensitive to the soil parameters, especially during wet periods. However, the evapotranspiration is also sensitive to some vegetation parameters and, during dry periods, wilting point is the most critical for evapotranspiration predictions. This result confirms the importance of correct representation of vegetation properties which, in water-limited conditions, control evapotranspiration.
\end{abstract}

Keywords: evapotranspiration, sensitivity analysis, land surface model, eddy correlation, Alpine basin

\section{Introduction}

The exchange of heat and moisture between the land surface and the atmosphere controls surface water and energy balances, which are critical to both hydrological models (flood forecasting, water resources planning and irrigation) and atmospheric models (e. g. Rosso, 1994; Brubaker and Entekhabi, 1995; Hu and Islam, 1996).

Land-surface models (LSMs) have been developed for estimating latent and sensible heat fluxes between the land surface and atmosphere in conjunction with a local water and energy balance (Noilhan and Planton, 1989; Famiglietti and Wood, 1994; Wigmosta et al., 1994; Albertson and Kiely, 2001; Montaldo and Albertson, 2001). Recent developments have made LSMs more complex by inclusion of more processes and controlling variables (Franks et al., 1997). These parameter additions are justified on the basis that the inclusion of additional controlling mechanisms should both improve predictive skill and make the parameter values more easily estimated on the basis of physiological characteristics or measurements. But these parameters are difficult enough to estimate in an experimental basin; in ungauged catchments lacking specific field campaign data the task is daunting. Moreover, in distributed applications of LSMs, the LSM parameterisation has to be applied at larger spatial scales, increasing the uncertainty of the parameterisation (Beven, 1995; Giorgi and Avissar, 1997; Bashford et al., 2002).

Indeed, results from the Project for Intercomparison of 
Land surface Parameterization Schemes (PILPS) (Henderson-Sellers et al., 1993) showed a wide range in predicted water and energy balances, highlighting the great uncertainty in the modelling of latent heat flux by LSMs (Pitman et al., 1999). Koster and Milly (1997) studied the wide disparity in LSM predictions of PILPS and found most differences between water and energy balances to be due to the relationships relating drainage and evapo-transpiration to soil moisture.

To overcome these uncertainties, significant efforts are being made to: (1) measure land surface fluxes and soil moisture for quantifying the partitioning of the water and energy balance at the land surface (e.g. Jackson, 1997; Halldin et al., 1999; Lai and Katul, 2000; Albertson and Kiely, 2001); (2) reduce model parameterisation and simplify the models through sensitivity analysis of LSMs to model parameters (e.g. Hu and Islam, 1996; Franks et al., 1997; Finch, 1998; Cayrol et al., 2000). With this last objective, Franks et al. (1997) performed a sensitivity analysis of evapotraspiration to parameters of a simplified LSM, using an innovative global multivariate technique, which allows for investigation of the sensitivity to each parameter, while varying all the other parameters. They identified some parameters that were much less important than others, thus suggesting the possibility of reducing the number of parameters. However, their model is arguably oversimplified, especially with respect to the dependence of plant transpiration on soil moisture, thus limiting somewhat the applicability of the conclusions.

Finch (1998) performed a univariate sensitivity analysis (variation of a single parameter at a time) of the groundwater recharge simulated by a LSM for a 23 -year observation period of a wet climate site in England. He found sensitivity to the vegetation canopy type (i.e. short vegetation $v$. forest), and to soil parameters, but relatively reduced sensitivity to vegetation functional parameters. The Finch finding is quite possibly limited to the prevailing wet conditions of the study. Along these lines, Albertson and Kiely (2001) demonstrated distinctly different sensitivity of the structure of soil moisture time series to model parameters in wet conditions, when drainage is the dominant process, than in drier conditions, when transpiration is the dominant loss mechanism.

The Toce basin analysis is a case study of the RAPHAEL (Runoff and Atmospheric Processes for flood HAzard forEcasting and controL) European Union research project, whose overall objective was to improve flood forecasting in complex mountain catchments, and with a specific objective to improve techniques for distributed land surface flux estimations. The points raised in the literature review and the need to support accurate distributed modelling for the RAPHAEL project, combine to form the motivation for this study. Therefore, prior to applying a distributed LSM over the whole Toce basin, a $1780 \mathrm{~km}^{2}$ catchment located in the Italian Alps, a field campaign was first conducted on an experimental plot within the basin, located in Pieve Vergonte, and the data used to explore the sensitivity of evapotranspiration to major model parameters in this region. The observation period was during the summer and autumn of 1999, which included both wet and dry periods, and was part of the Mesoscale Alpine Program Special Observing Periods (MAP-SOP).

Measurements of meteorological variables and energy fluxes were performed. On the basis of the data set collected here, the skill and parameter importance (sensitivity) was explored in an existing LSM, the TOPLATS model of Famiglietti and Wood (1994), which is widely used by the meteorological and hydrological communities (Houser et al., 1998; Endreny et al., 2000; Bashford et al., 2002; Pauwels et al., 2002). In this case study the TOPLATS model is applied at the local scale and a comparison made between measured and simulated evapotranspiration rates to evaluate the LSM performance. Finally, using the global multivariate technique, a sensitivity analysis of the evapotranspiration to model parameters is performed separately for wet and dry periods (Albertson and Kiely, 2001), thus allowing a view of the conditional sensitivities. In this way, the following objectives were addressed: (1) test the performance of TOPLATS for evapotranspiration estimates in an Alpine field trough; (2) investigate the relative importance of TOPLATS parameters with respect to evapotranspiration estimates, conditioned (i.e. segmented) on mean hydro-meteorological conditions, including both atmosphere-controlled and water-limited periods.

\section{Pieve Vergonte field campaign}

\section{STUDY SITE}

The research field site is at Pieve Vergonte $\left(8.283^{\circ}\right.$ Longitude and $46.017^{\circ}$ Latitude), in the Toce valley (North Piedmont, Italy). The Toce catchment is an alpine basin with steep hillslopes bounding a narrow valley, with a total drainage area of about $1780 \mathrm{~km}^{2}$, and an elevation range of 193$4615 \mathrm{~m}$ a.s.l. The research field is principally grassland (fraction of vegetation cover $\sim 0.8$ ) located at an elevation of approximately $210 \mathrm{~m}$ a.s.l. The grass heights vary through the growing season from $20 \mathrm{~cm}$ to $100 \mathrm{~cm}$. The root zone depth is estimated at about $50 \mathrm{~cm}$.

The local climate is typically Alpine, humid with higher precipitations in autumn and spring and lower in winter. The mean annual precipitation is approximately $1500 \mathrm{~mm}$. 


\section{SOIL PROPERTIES}

The soil texture composition is estimated using the USDA classifications from the particle size distribution curve (e.g. Kutílek and Nielsen, 1994). Soil samples were taken at depths of $0-5,10-15,15-20,30-35,40-45$ and $46-50 \mathrm{~cm}$ and the particle size distribution curve was estimated for each sample using the dry sieving method. The soil can be classified as sandy loam in the first $40 \mathrm{~cm}$ and as loamy sand below.

A direct measurement of the saturated hydraulic conductivity was also performed in the field with a Guelph permeameter (Reynolds et al., 1985; Reynolds and Elrick, 1985), model 2800KI of the Soil Moisture Equipment Corp. (Santa Barbara, CA. USA). Measurements at two soil depths, 20 and $50 \mathrm{~cm}$, were performed and values of the saturated hydraulic conductivity were equal to, respectively, $3.4 \times$ $10^{-5} \mathrm{~m} \mathrm{~s}^{-1}$ and $2.7 \times 10^{-5} \mathrm{~m} \mathrm{~s}^{-1}$.

\section{EVAPOTRANSPIRATION ESTIMATES}

Meteorological measurements and evapotranspiration estimates were performed from the 29th of June to the 9th of July and from the 4th of August to the 10th of November 1999.

The micrometeorological station was equipped with two aspirated dry/wet bulb psychrometers H301 (at heights of $1.7 \mathrm{~m}$ and $2.8 \mathrm{~m}$ ), a wind speed anemometer A100R (at $3.2 \mathrm{~m}$ ), a wind vane potentiometer W200P and a wind monitor 05103 (at the height of $2.8 \mathrm{~m}$ ), a net radiometer Q7, two soil heat flux probes HFT3, two soil temperature probes TCAV (at a depth of $5 \mathrm{~cm}$ ), a tipping bucket raingauge ARG100, and a barometric pressure sensor PTA427; the datalogger recording all the measurements was a CR10, with one multiplexer AM416, by Campbell Scientific Inc. (Logan, Utah). All the data were recorded as averages over a halfhour time resolution.

During the first observation period (days 180-189 of 1999) measurements of latent and sensible heat exchange between the land and the atmosphere were performed with an eddy correlation system. It was equipped with a Krypton Hygrometer KH20, a three-dimensional sonic anemometer CSAT3 and a fine wire thermocouple FWTCSAT, joined together through a $21 \mathrm{X}$ datalogger (all supplied by Campbell Scientific Inc. Systems, Logan, Utah). Bowen ratio estimates of evapotranspiration rates are available for the full campaign period (Montaldo et al., 2001).

Actual evapotranspiration rates estimated by the energy balance-Bowen ratio method and the eddy correlation method are compared for the first period. The energy balance-Bowen ratio method estimates latent heat flux $(\lambda E)$ and sensible heat flux $(H)$ from the application of the energy balance with observations of the vertical gradients of temperature and water vapour between the land and atmosphere (Brutsaert, 1982). Because the fluxes are estimated at a fine time resolution ( $<1$ hour), the corrections for the atmospheric stability are included in the evaporation estimates (Brutsaert, 1982). The eddy correlation method measures turbulent fluctuations in vertical wind speed, air temperature and humidity, from which latent and sensible heat fluxes are determined (Brutsaert, 1982).

The latent and sensible heat fluxes estimated by the eddy correlation method are shown in Fig. 1(a), where the main terms of the energy balance for the first period are compared. This period was relatively dry (water-limited conditions) with net radiation fluxes $\left(R_{\mathrm{n}}\right)$ as high as $700 \mathrm{~W} \mathrm{~m}^{2}$, while the ground heat flux $(G)$ reached a maximum of $26 \mathrm{~W} \mathrm{~m}^{2}$ into the soil (Fig. 1(a). Note that the increase of $\lambda E$ on the last day (n. 188) in Fig. 1 is due to a rain event.

The scatter plot of Fig. 2, compares eddy correlation and the Bowen ratio derived latent heat flux estimates; the correlation coefficient between the two methods is 0.89 , confirming good agreement. The cloud of high points for the energy balance latent heat flux estimates (of about 500 $\mathrm{W} \mathrm{m}^{-2}$ ) are from the last day of the period, just after the rainfall event reported in Fig. 1(b).

Cumulative evapotranspiration (ET) values estimated by the two methods are compared in Fig. 1(b). ET cumulative values estimated by the eddy correlation and energy balance methods are equal (about $18 \mathrm{~mm}$ ) at the end of the observed period, confirming the good agreement of measurements. For context, Fig. 1 also shows the cumulative potential evapotranspiration (PET) estimated by the PenmanMonteith equation (e.g. Brutsaert, 1982). The potential evapotranspiration is significantly higher than the actual evapotranspiration because dry hydro-meteorological conditions determine water limited conditions, i.e. low soil moisture and low rates for actual ET compared to PET.

During the second observation period, the eddy correlation system was not available. Furthermore, for the portion of the second observation period following 15 October (day 288), the Bowen ratio station estimates became unreliable because very humid conditions made accurate vertical gradient estimates problematic (Montaldo et al., 2001), so that measurements of the mean meteorological variables are available from this date only. Figure 3 depicts the main terms of the energy balance: net radiation and soil heat flux for the full measurement period, while sensible and latent heat fluxes estimated by the energy balance-Bowen ratio method are presented only up to day 287. Peak daytime $R_{\mathrm{n}}$ values decreased from about $600 \mathrm{~W} \mathrm{~m}^{2}$ in August to $200-300 \mathrm{~W} \mathrm{~m}^{2}$ and less in October and November. $R_{\mathrm{n}}$ and $\lambda E$ reductions are also evident during cloudy and stormy periods (see, for 

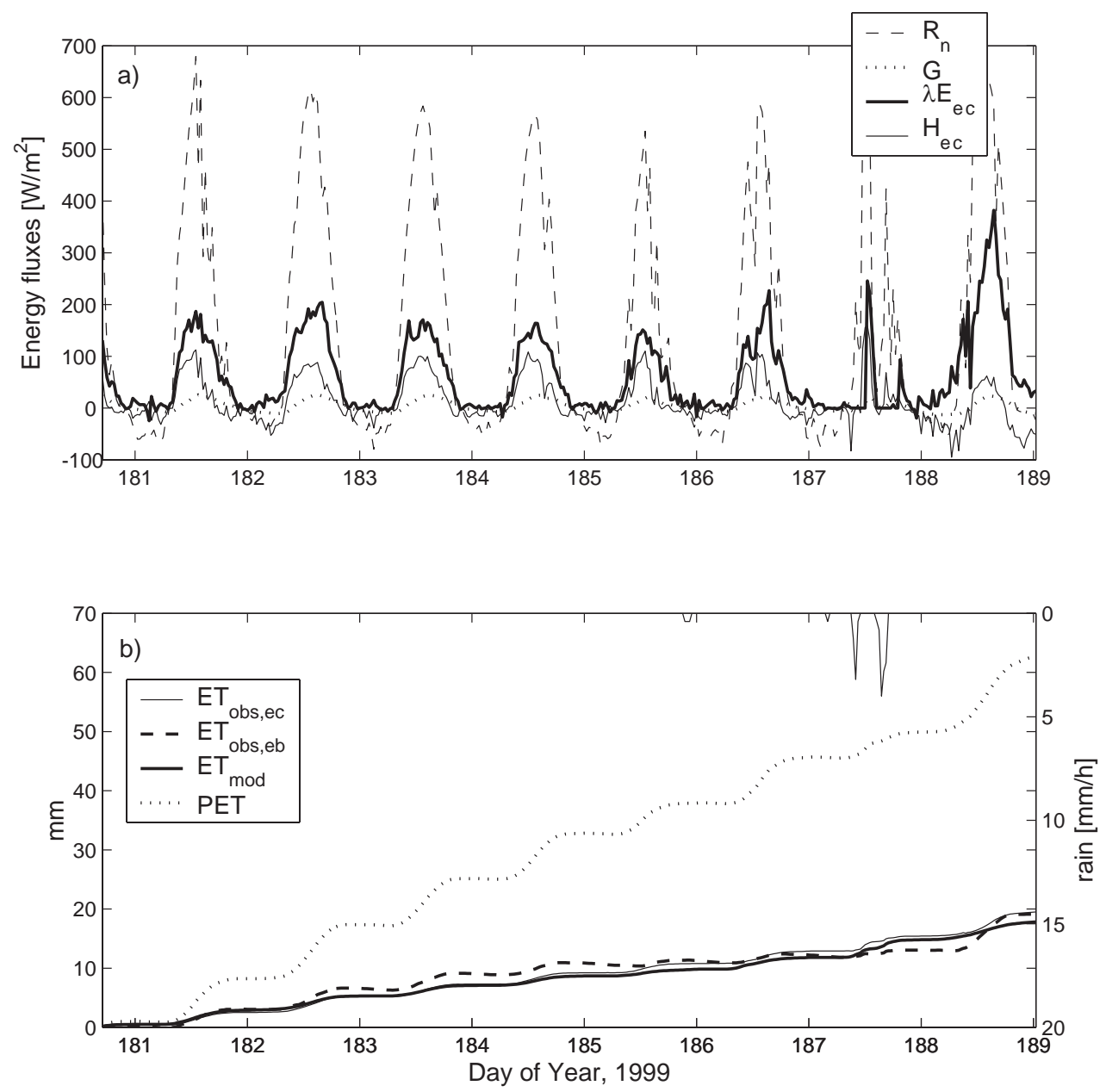

Fig. 1. For the first observation period: (a) main terms of the energy balance; (b) cumulated values of modelled (ET $T_{\text {mod }}$ ) and observed (ET $T_{\text {obsec }}$ and $E T_{\text {obse, }, \text { }}$ ) obtained through the eddy correlation and the energy balance-Bowen ratio methods respectively, the potential evapotranspiration (PET), and the rainfall.

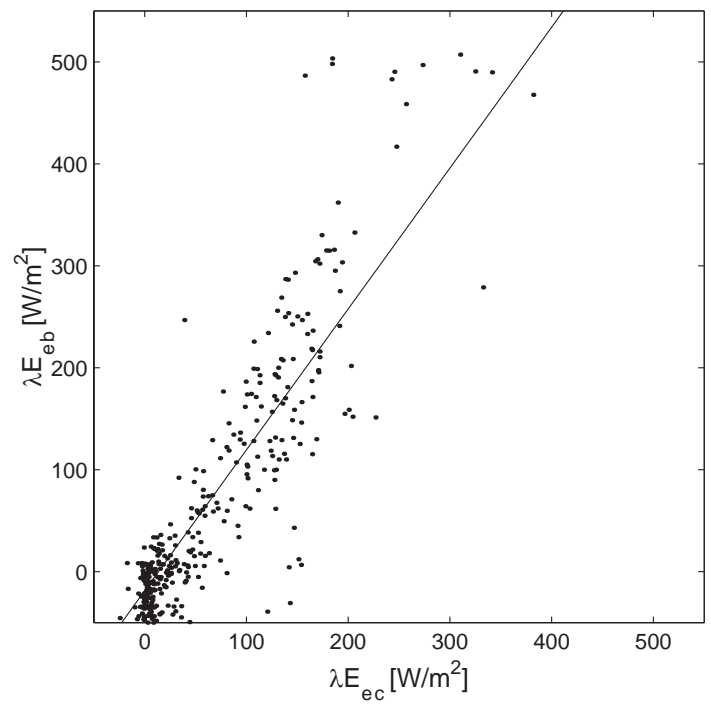

Fig. 2. For the first observation period (180-189) scatter plot of estimated latent heat flux values obtained by the eddy correlation method $\left(\lambda E_{e d}\right)$ and the energy balance method $\left(\lambda E_{e b}\right)$. instance, the periods 261-263 and 293-298). Compared to $\lambda E$ estimates of the previous dry period, $\lambda E$ values for this second period are closer to $R_{\mathrm{n}}$ values because the hydrometeorological conditions are wetter, i.e. more atmosphere-controlled. This result is confirmed by the graph of Fig. 4(a), in which cumulative values of the actual and potential evapotranspiration are compared. The cumulative value of the ET at the end of the 216-287 period is about $160 \mathrm{~mm}$, while the cumulative value of PET at the end of the period is about $213 \mathrm{~mm}(E T / P E T=0.75)$ confirming that ET rates were close to PET rates, except during the 247-262 period, which was the driest of the whole AugustNovember observation period.

For the final observation period (287-314 day), only meteorological measurements are available, so that only an estimate of the potential evapotraspiration is presented (Fig. 4(b)). 

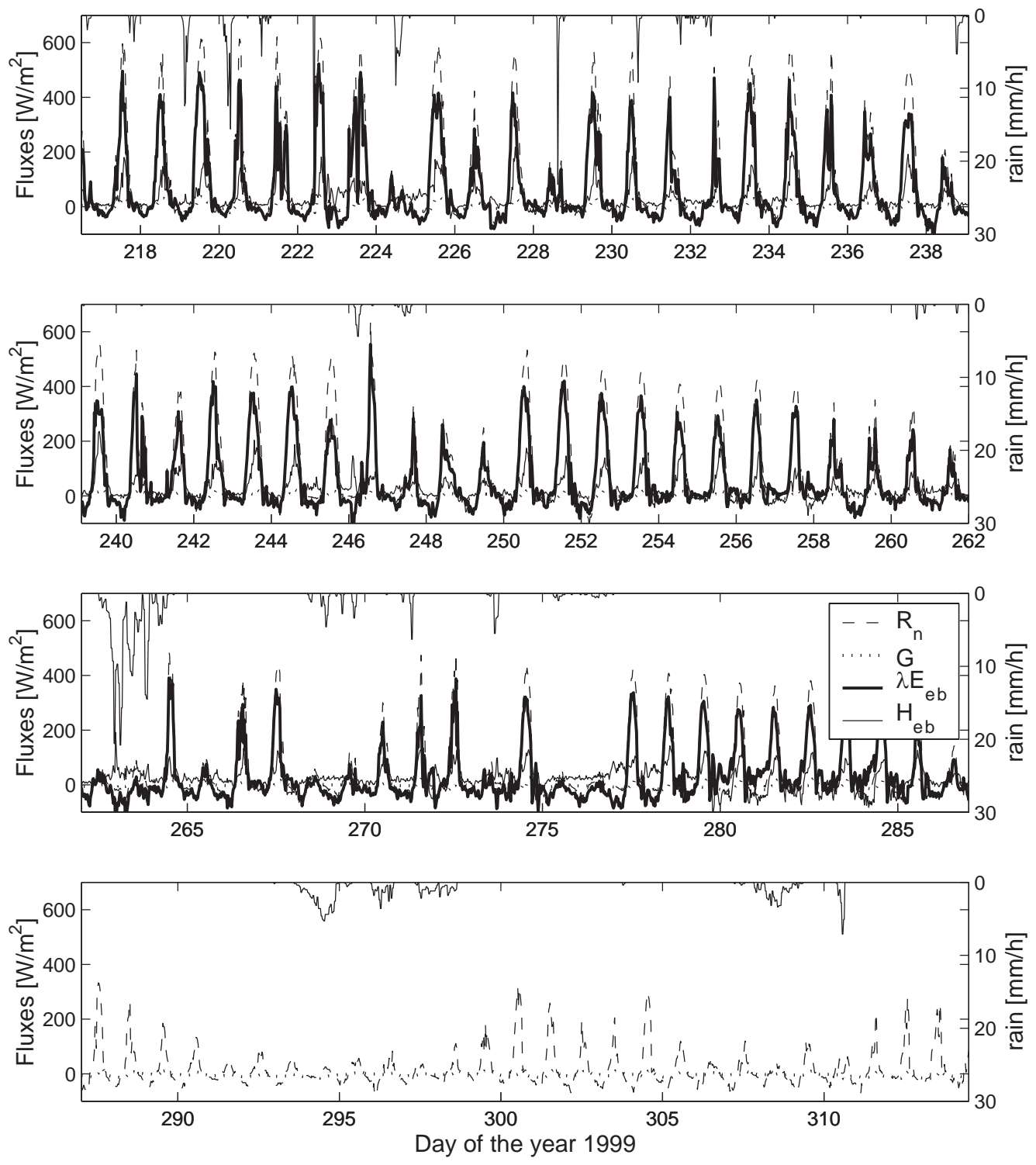

Fig. 3. Main terms of the energy balance and rainfall for the 216-314 day observation period.

\section{The land surface model and its application to the Pieve Vergonte case study}

A brief description of the LSM and its calibration and validation for the Pieve Vergonte field campaign data set are reported in the following subsections.

\section{TOPLATS MODEL DESCRIPTION}

The TOPLATS land-surface model of Famiglietti and Wood (1994) predicts the dynamics of water and energy fluxes at the land surface and the local recharge to the water table on a sub-daily time step.
A canopy water balance equation simulates the interception storage (its capacity is a function of the leaf area index, $L A I$ ), and distinguishes between wet and dry canopies. The land surface is partitioned into bare soil and vegetated components. The sub-surface soil column is divided into two layers: an upper layer (root zone) and a lower layer (transmission zone). The root zone supplies the bare-soil and vegetation with soil moisture for evapotranspiration, and controls the infiltration and runoff mechanisms. The less active transmission zone extends from the base of the root zone to the top of the capillary fringe, which overlies the water table. The base of the transmission zone represents the lower boundary of the LSM.

In the unsaturated soil, the Brooks and Corey (1964) 

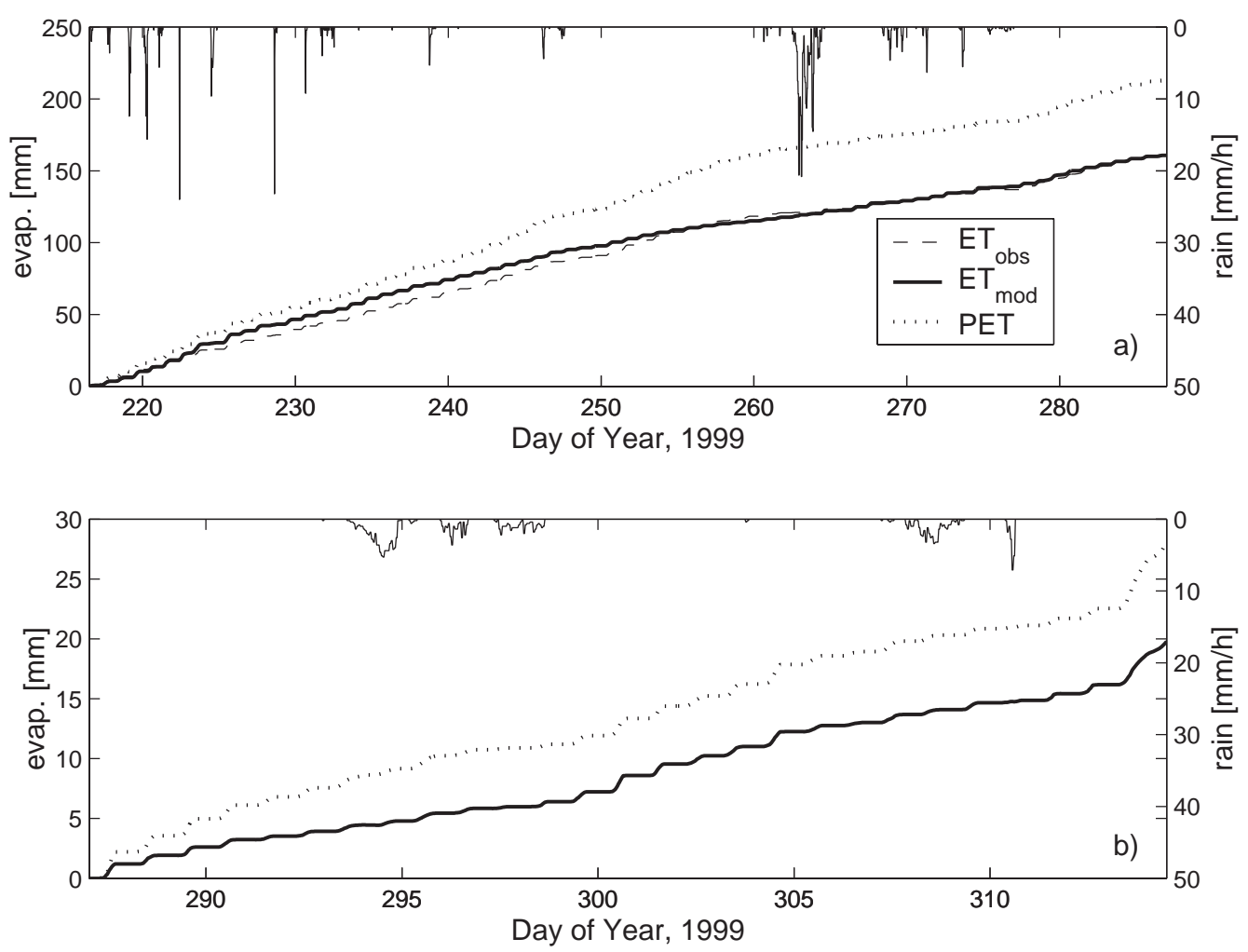

Fig. 4. Cumulated values of modelled (ETmod) and observed (ETobs) evapotranspiration, and the potential evapotranspiration (PET) for: (a) the 216-287 day observation period; (b) the 287-314 day observation period.

relationships are used to describe the non-linear dependencies of soil moisture $(\theta)$ and hydraulic conductivity $(k)$ on the matric potential $(\psi)$

$$
\begin{gathered}
\psi=\psi_{b}\left(\frac{\theta_{s}-\theta_{r}}{\theta-\theta_{r}}\right)^{\frac{1}{B}} \\
k=k_{s}\left(\frac{\psi_{b}}{\psi}\right)^{2+3 B}
\end{gathered}
$$

where $k_{s}$ is the saturated hydraulic conductivity, $\theta_{s}$ and $\theta_{r}$ are the saturated and residual soil moisture respectively, $B$ is the pore size distribution index, and $\psi_{b}$ is the air entry suction head.

Runoff generation in the model occurs by both infiltration excess and saturation excess mechanisms. The actual infiltration rate is taken as the minimum of the precipitation rate (or throughfall in the case of vegetated soil) and an infiltration capacity, which is given by Milly (1986) in terms of cumulative infiltration, soil properties and the root zone moisture content at the start of the storm event, and is based on the Philip (1957) infiltration equation.

In both root and transmission zones, the soil moisture evolution is described by typical water balance equations, which are different with respect to the local water table depth that can lie within the root zone or beneath the bottom of the root zone (Famiglietti and Wood, 1994). Here only the general water balance equation of the root zone is reported for the case of the local water table depth beneath the bottom of the root zone

$$
\frac{\partial \theta_{r z}}{\partial t}=\frac{1}{d_{r z}}(I+\omega-E T-G)
$$

where $\theta_{r z}$ is the root zone soil moisture, $d_{r z}$ is the root zone depth, $I$ is the infiltration, $\omega$ is the capillary flux, $E T$ is the evapotranspiration, and $G$ is the drainage, which is estimated by (2) using the unit head gradient assumption (e.g. Kutilek and Nielsen, 1994). Downward soil water fluxes through the transmission zone include the drainage flux from the root zone $(G)$, and a drainage flux out of the transmission zone. Upward water fluxes through the root zone include evaporation from bare soils and the transpiration, and the upward capillary fluxes, which pass from the water table through the transmission zone and into the root zone. Details of model equations are reported in Famiglietti and Wood (1994). For context, here only the model equations for the actual evapotranspiration estimate are reviewed.

The global actual evapotranspiration flux is given by 


$$
E T=f_{b s} E_{b s}+f_{v}\left[E_{w c}+T\right]
$$

where $E_{b s}$ is the actual rate of bare soil evaporation, $E_{w c}$ is the actual evaporation rate from wet canopy, $T$ is the actual rate of transpiration, and $f_{b s}$ and $f_{v}$ are the fraction of the bare soil and the vegetation area respectively $\left(f_{b s}+f_{v}=1\right)$. The actual rate of bare soil evaporation is determined by taking the minimum of the potential evaporation rate, estimated by the Penman equation (e.g. Brutsaert, 1982), and the exfiltration capacity given by Milly (1986). The evaporation from the wet canopy is a function of the fraction of the wet canopy estimated dynamically by the interception storage water balance equation. The evaporation from exposed soil has relatively minor impact on root-zone soil moisture, since $T \gg E_{b s}$ over well-vegetated sites as addressed here. The transpiration flux of water from the root zone is estimated as

$$
T=\beta(\theta) E T_{\text {unst }}
$$

where $\beta$ captures the effect of soil moisture on transpiration $(0 \leq \beta \leq 1)$ as described below, and $E T_{\text {unst }}$ is given by the Penman-Monteith equation

$$
E T_{\text {unst }}=\frac{\Delta\left(R_{n e t}-G\right)+\rho_{a} c_{p}\left(e_{s}-e_{a}\right) / r_{a}}{L_{v} \rho_{w}\left[\Delta+\gamma\left(1+\frac{r_{c}}{r_{a}}\right)\right]}
$$

where $L_{v}$ is the latent heat of vaporisation of water, $\Delta$ the slope of the saturation vapour pressure curve, $e_{s}$ the saturated vapour pressure, $e_{a}$ the vapour pressure, $\gamma$ the psychrometric constant, $\rho_{\mathrm{w}}$ the water density, $\rho_{\mathrm{a}}$ the air density, $c_{p}$ the specific heat of air, $r_{c, \min }$ is the minimum canopy resistance given by $r_{s, \text { min }}=r_{s, \text { min }} / \mathrm{LAI}$, where $r_{s, \text { min }}$ is a minimum value of stomatal resistance, and $r_{a}$ is the aerodynamic resistance given by

$$
r_{a}=\frac{\left[\ln \left(\frac{z_{m}-d}{z_{o}}\right)\right]^{2}}{k^{2} u\left(z_{m}\right)}
$$

where $d$ is the zero plane displacement, $z_{o}$ is the roughness length, $k$ is the von Kármán's constant, $u\left(z_{m}\right)$ is the wind speed at level $z_{m}$. Note that the model does not distinguish between momentum and water vapour roughness lengths (e.g. Brutsaert, 1982). Finally the $\beta$ term of (5) is

$$
\beta\left(\theta_{r z}\right)= \begin{cases}0, & \text { for } \quad \theta_{r z} \leq \theta_{w p} \\ \frac{\theta_{r z}-\theta_{w p}}{\theta_{\lim }-\theta_{w p}}, & \text { for } \quad \theta_{w p}<\theta_{r z}<\theta_{\lim } \\ 1, & \text { for } \theta_{r z} \geq \theta_{\lim }\end{cases}
$$

where $\theta_{\text {lim }}$ and $\theta_{w p}$ are parameters that define the states at which soil moisture becomes limiting and eventually causes vegetation to wilt and transpiration to cease, respectively.

Table 1 reports the model parameters: the first six are soil parameters while the last eight are vegetation parameters. The model is driven with standard meteorological data at a time resolution of half an hour.

\section{MODEL CALIBRATION AND VALIDATION}

Model calibration is performed by comparing observed and simulated actual evapotranspiration rates for the 216-287

Table 1. Model parameters, their calibrated values, and the range of values assigned to each parameter in the sensitivity analysis.

\begin{tabular}{llll}
\hline Parameter & Description & Calibrated value & Range \\
\hline$k_{s}\left[\mathrm{~m} \mathrm{~s}^{-1}\right]$ & saturated hydraulic conductivity & $10^{-5}$ & $10^{-6}-10^{-4}$ \\
$\theta_{s}$ & saturated soil moisture & 0.453 & $0.38-0.52$ \\
$\theta_{r}$ & Residual soil moisture & 0.041 & $0.01-0.07$ \\
$\beta$ & pore size distribution index & 0.38 & $0.28-0.48$ \\
$\psi_{b}[\mathrm{~m}]$ & air entry suction head & 0.15 & $0.07-0.25$ \\
$d_{r z}[\mathrm{~m}]$ & root zone depth & 0.5 & $0.3-0.7$ \\
$z_{o, d v}[\mathrm{~m}]$ & dry canopy roughness length & 0.05 & $0.01-0.15$ \\
$d_{d v}[\mathrm{~m}]$ & dry canopy zero plane displacement & 0.23 & $0.13-0.33$ \\
$z_{o, w v}[\mathrm{~m}]$ & wet canopy roughness length & 0.05 & $0.01-0.15$ \\
$d_{w v}[\mathrm{~m}]$ & wet canopy zero plane displacement & 0.23 & $0.13-0.33$ \\
$r_{s, \min }\left[\mathrm{s} \mathrm{s} \mathrm{s}^{-1}\right]$ & minimum stomatal resistance & 75 & $20-200$ \\
$L_{A I}$ & leaf area index & 2.5 & $0.5-4$ \\
$\theta_{l i m}$ & limiting soil moisture for vegetation & 0.27 & $0.22-0.32$ \\
$\theta_{w p}$ & wilting point & 0.12 & $0.07-0.17$ \\
\hline
\end{tabular}


day-period, and minimising the root mean square error (RMSE) and the $\eta$ model efficiency of Nash and Sutcliffe (1970) defined as

$$
\eta=1-\frac{\sum_{i=1}^{n_{i}}\left(E T_{m, i}-E T_{o, i}\right)^{2}}{\sum_{i=1}^{n_{i}}\left(E T_{o, i}-\overline{E T_{o}}\right)^{2}}
$$

where $n_{t}$ is the total number of time steps, $E T_{o, i}$ and $E T_{m, i}$ are the observed and modelled evapotranspiration at time step, $i$, respectively, and $\overline{E T}$ is the mean of the observed evapotranspiration. The third column of Table 1 reports the calibrated values of the model parameters. The water table depth initial condition was set equal to $4 \mathrm{~m}$ according to measurements made in wells nearby, and did not change significantly during the full observation period.

Soil parameters are derived by class pedotransfer functions (PTFs), as they enable the estimation of soil hydraulic characteristics directly from soil texture. The values suggested by Rawls et al. (1982) were used, which refer to the soil parameters of the Brooks and Corey equations. The $k_{s}$ saturated hydraulic conductivity value is fixed greater $\left(=10^{-5} \mathrm{~m} \mathrm{~s}^{-1}\right)$ than the value suggested by Rawls et al. (1982) (which is $5 \times 10^{-6} \mathrm{~m} \mathrm{~s}^{-1}$ ), because both the measurements obtained with the Guelph permeameter and the calibration of the LSM suggested higher values. Vegetation parameters are first estimated from literature data and then refined through calibration.

The comparison of modelled and observed actual evapotranspiration rates for the second observation period

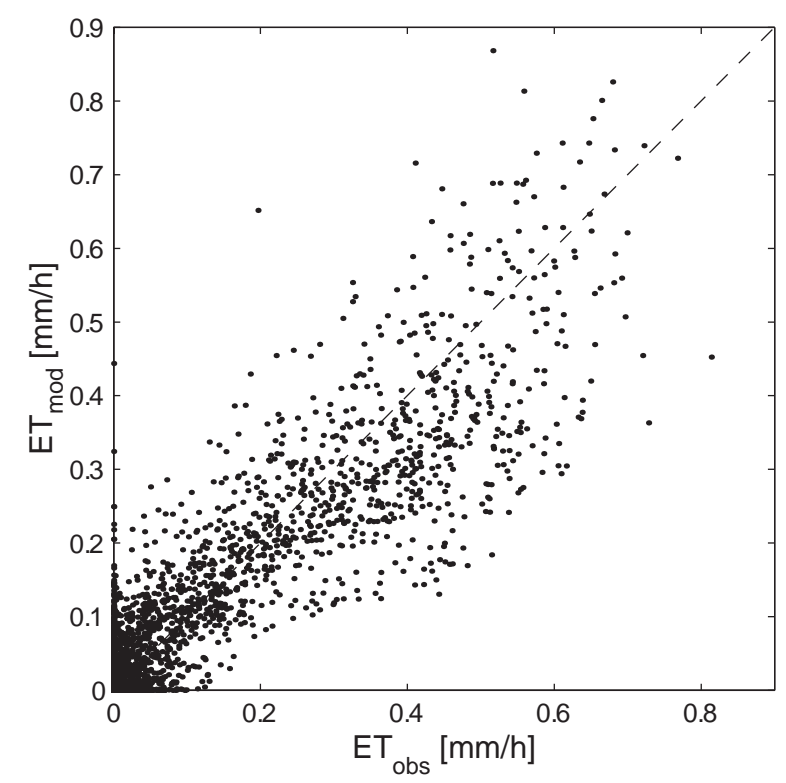

Fig. 5. The 216-287 day observation period scatter plot of modelled $\left(E T_{\text {mod }}\right)$ and observed ( $E T_{\text {obs }}$ ) evapotranspiration values. is reported in the scatter plot of Fig. 5. The correlation coefficient is 0.905 , the model efficiency is 0.82 , and the RMSE value is 0.068 for the hourly comparison. For the first observation period, the RMSE of the simulation is 0.04 , $\eta$ is 0.824 , and the correlation coefficient is 0.92 (Fig. 1b). Hence, since the observed and modelled ET rates are similar both in local-in-time sense and when integrated to express the total impact to the surface water balance (Fig. 1b and Fig. 4a), it is concluded that the model calibration was effective.

Finally, simulated actual evapotranspiration and estimated potential evapotranspiration values are compared for the last observed period (287-314 days) in which actual ET observations are not available, and the process is principally atmosphere controlled (Figure 4(b)).

\section{Sensitivity analysis of the land surface model}

The TOPLATS model is characterised by the parameters of Table 1, many of which are difficult — and at times costly to estimate. A sensitivity analysis of model responses to input parameter values can highlight their relative importance for the site and guide the prioritisation of parameter estimation efforts.

\section{SENSITIVITY ANALYSIS PROCEDURE}

To understand the influence of the model parameters on ET estimation in the context of the type of prevailing hydrometeorological conditions, the whole observation period is divided into four sub-periods, characterised by different hydro-meteorological conditions. Table 2 reports the days included in each sub-period, and the mean temperature, the mean net radiation, the cumulative potential evapotranspiration $\left(P E T_{\mathrm{t}}\right)$, the cumulative rainfall $\left(P_{\mathrm{t}}\right)$, and the ratio of $P E T / P$, which is adopted as an index of dryness (in a hydrometeorological forcing sense). In progressing from summer to autumn, the climatic conditions clearly became wetter and colder, the mean temperature and the mean net radiation decreased, and the $P E T_{\mathrm{t}} / P_{\mathrm{t}}$ ratio decreased. At the same time, the average modelled root zone soil moisture values $\left(\overline{\theta_{r z}}\right)$ of each sub-period (obtained with the calibrated parameter values of Table 1) increased as the conditions became wetter (last column of Table 2).

The sensitivity analysis of the model was performed through a global multivariate approach, which allowed for analysis of the influence of each parameter, while varying all the other parameters at the same time. The methodology of Franks et al. (1997) was used, which is an extension of the Regional Sensitivity Analysis (Spear and Hornberger, 
Table 2. Mean temperature $(\bar{T})$, net radiation $\left(\overline{R_{n}}\right)$, total cumulative potential evapotranspiration $\left(P E T_{t}\right)$, cumulative rainfall $\left(P_{t}\right)$, the $P E T_{t} / P_{t}$ ratio, and the average simulated root zone soil moisture $\left(\bar{\theta}_{r z}\right)$ for the four selected sub-periods.

\begin{tabular}{lllllrll}
\hline Sub-period & Sub-period days & $\bar{T}\left[{ }^{\circ} \mathrm{C}\right]$ & $\bar{R}_{n}\left[\mathrm{~W} \mathrm{~m}{ }^{-2}\right]$ & $P E T_{t}[\mathrm{~mm}]$ & $P_{t}[\mathrm{~mm}]$ & $P_{E T / P}$ & $\bar{\theta}_{r z}$ \\
\hline 1 & $180-189$ & 26.18 & 143.70 & 62.63 & 8.40 & 7.456 & 0.15 \\
2 & $216-262$ & 23.05 & 96.02 & 165.34 & 158.91 & 1.041 & 0.21 \\
3 & $262-287$ & 17.55 & 50.00 & 47.54 & 304.12 & 0.156 & 0.24 \\
4 & $287-314$ & 14.03 & 15.27 & 28.103 & 193.20 & 0.145 & 0.26 \\
\hline
\end{tabular}

1980; Spear et al., 1994). The approach is based on a Monte Carlo simulation framework. A uniform sampling strategy is used, assuming that all parameters varied independently without taking possible correlation among parameter values into consideration. In the analysis, 10000 parameter sets are employed to sample the parameter range. A range of
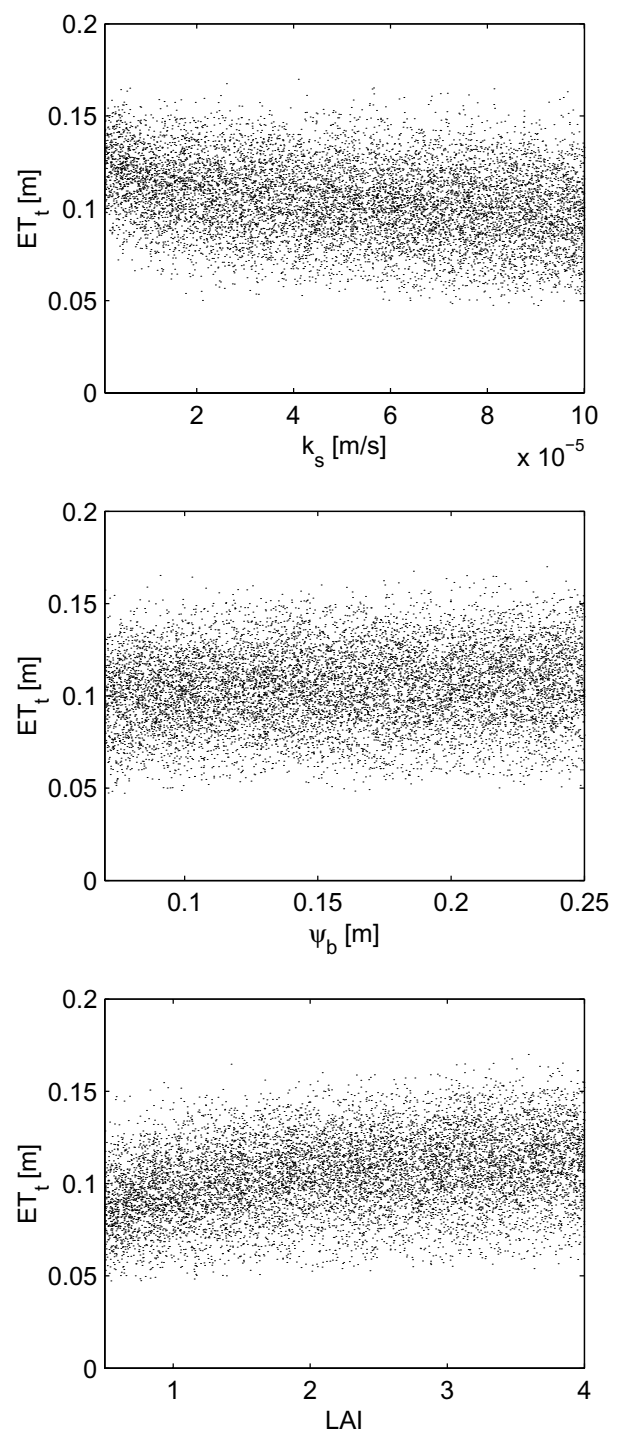

physically realistic values was assigned to each parameter to represent the uncertainty of parameter estimates or measurements (4th column of Table 1). For instance, Fig. 6(a) shows the range of modelled cumulative evapotranspiration across the range of six model parameters for the sub-period 2. In general, it can be seen that large
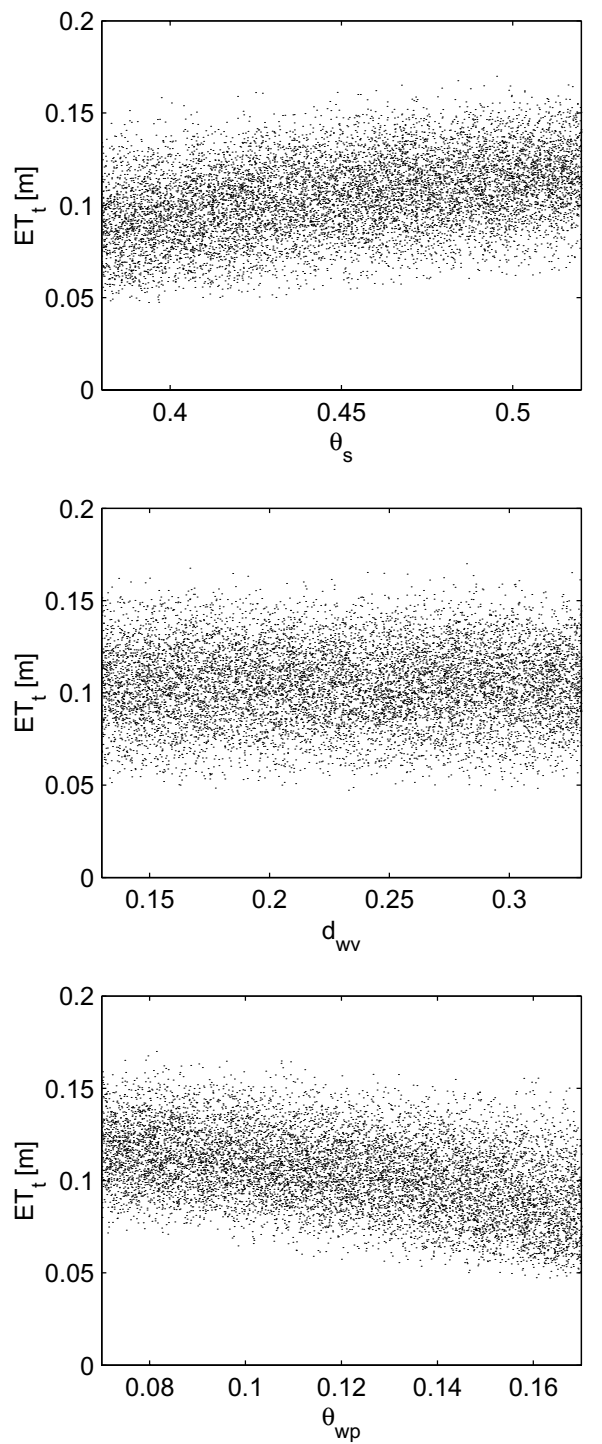

Fig. 6(a). For the sub-period 2: total cumulative evapotranspiration (ET) values plotted against six input model parameters. 

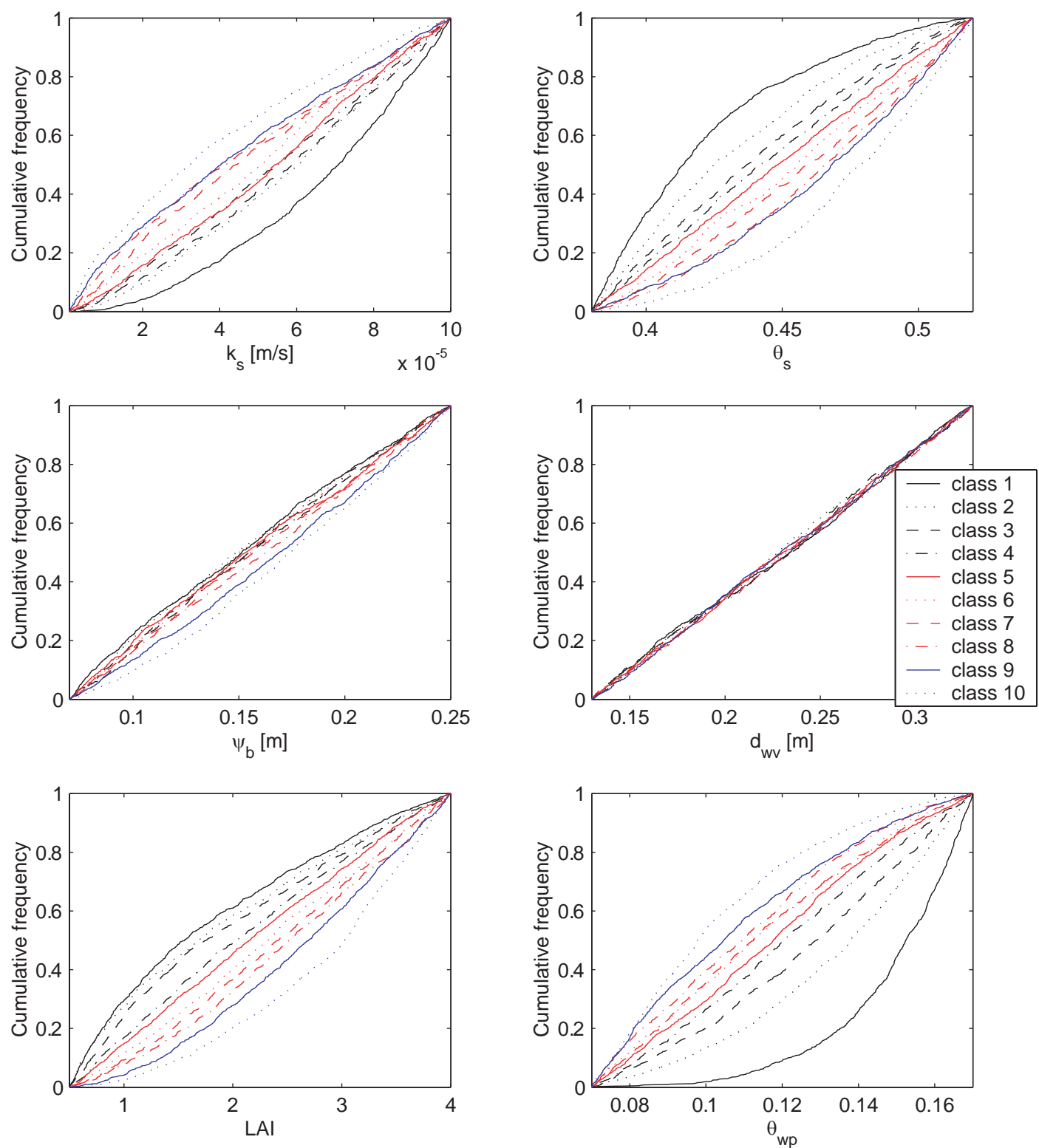

Fig. 6(b) For the sub-period 2: cumulative frequency of the ten performance classes versus the parameter range.

ranges of cumulative evapotranspiration are simulated for each parameter; however, the trend in the central tendency of the cumulative ET across variation in certain parameters is clearly more pronounced than for other parameters. The range of $E T_{t}$ values obtained at each parameter value is spread due to the range in the other parameters sampled for the given value of the parameter under consideration.

To carry out the sensitivity analysis of the TOPLATS model output, the 10000 realisations are ranked according to the cumulative evapotranspiration totals (Franks et al., 1997); ten performance classes of cumulative evapotranspiration are created by dividing the ranked realisations into groups of 1000 realisations, or sample parameter sets (note that the classes are ordered for increasing values of $E T_{\mathrm{t}}$ ). For instance, in this way, for the six model parameters of Fig. 6(a) the parameter cumulative distributions are obtained for the ten performance class plotted in Fig. 6(b). In general, the observation of nonuniform distributions for different performance classes indicates sensitivity of the cumulative evapotranspiration to that parameter: in fact, a straight line would indicate a uniform distribution reflecting insensitivity for that performance class, whereas a marked departure from a straight line would represent a non-uniform distribution reflecting sensitivity of the cumulative evapotranspiration to the subject parameter. For example, for the case examined 
in Fig. 6(b), the evapotranspiration is highly sensitive to $\theta_{w p}$, sensitive to $k_{s}, \theta_{s}$, and $L A I$, slightly sensitive to $\psi_{b}$, and non sensitive to $d_{w v}$.

This approach is repeated for all four periods.

\section{SENSITIVITY ANALYSIS RESULTS}

The sensitivity analysis results for all the four sub-periods allows elucidation of the role of each model parameter in the evapotranspiration process according to hydrometeorological conditions. For instance, Fig. 7 shows the $\theta_{w p}$ cumulative frequency of the 10 performance classes for the four hydro-meteorological classification sub-periods. The sensitivity of the evapotranspiration to $\theta_{w p}$ is higher for the dry sub-period than for wet sub-periods because in dry periods the vegetation is water-limited and soil moisture values are close to the wilting point, and changes in $\theta_{w p}$ translate directly into changes in ET through Eqns. (5) and (8).

The introduction of a numerical sensitivity index $\left(x_{s}\right)$ of the evapotranspiration to a generic parameter, $x$, as given by

$$
x_{s}=\frac{1}{n_{c} N x_{\text {range }}} \sum_{i=1}^{n_{c}} \sum_{j=1}^{N} x_{d}(j, i)
$$

where $x_{d}$ is the difference between the parameter values of two performance classes for a $j^{\text {th }}$ cumulative frequency and for a $i^{\text {th }}$ pair of cumulative frequency curves, $x_{\text {range }}$ is the range of parameter values (given by column 4 of Table 1), $N$ is the number of cumulative frequency values in each performance class ( $=1000$ in this case), $n_{c}$ is the total number of pairs of cumulative frequency classes (in this case, with 10 classes $n_{c}=45$ ) is made to quantify numerically and compare the results of the sensitivity analysis for all the parameters and sub-periods. Note that, in the denominator of (10), $x_{\text {range }}$ non-dimensionalises $x_{s}$.

The $x_{s}$ values are computed for all the parameters and for all the periods of Table 2 . The sensitivity indices of the parameters are plotted against the $P E T_{\mathrm{t}} / P_{\mathrm{t}}$ ratio of the respective sub-periods in Fig.8 (soil parameter results in Fig. 8(a) and vegetation parameter results in Fig. 8(b)).

In general, the evapotranspiration is sensitive to all the soil parameters, but the sensitivity to certain parameters changes according to hydro-meteorological conditions (Fig. 8(a)). For wet periods the drainage becomes more significant and the parameters related to it (see Eqn. (2)) become more important in the root zone water balance, and, consequently, in the flux modeling. Indeed, $k_{s}, \theta_{s}$ and $B$ affect evapotranspiration significantly in wet sub-periods, while their sensitivity indices decrease in the dry sub-period, in
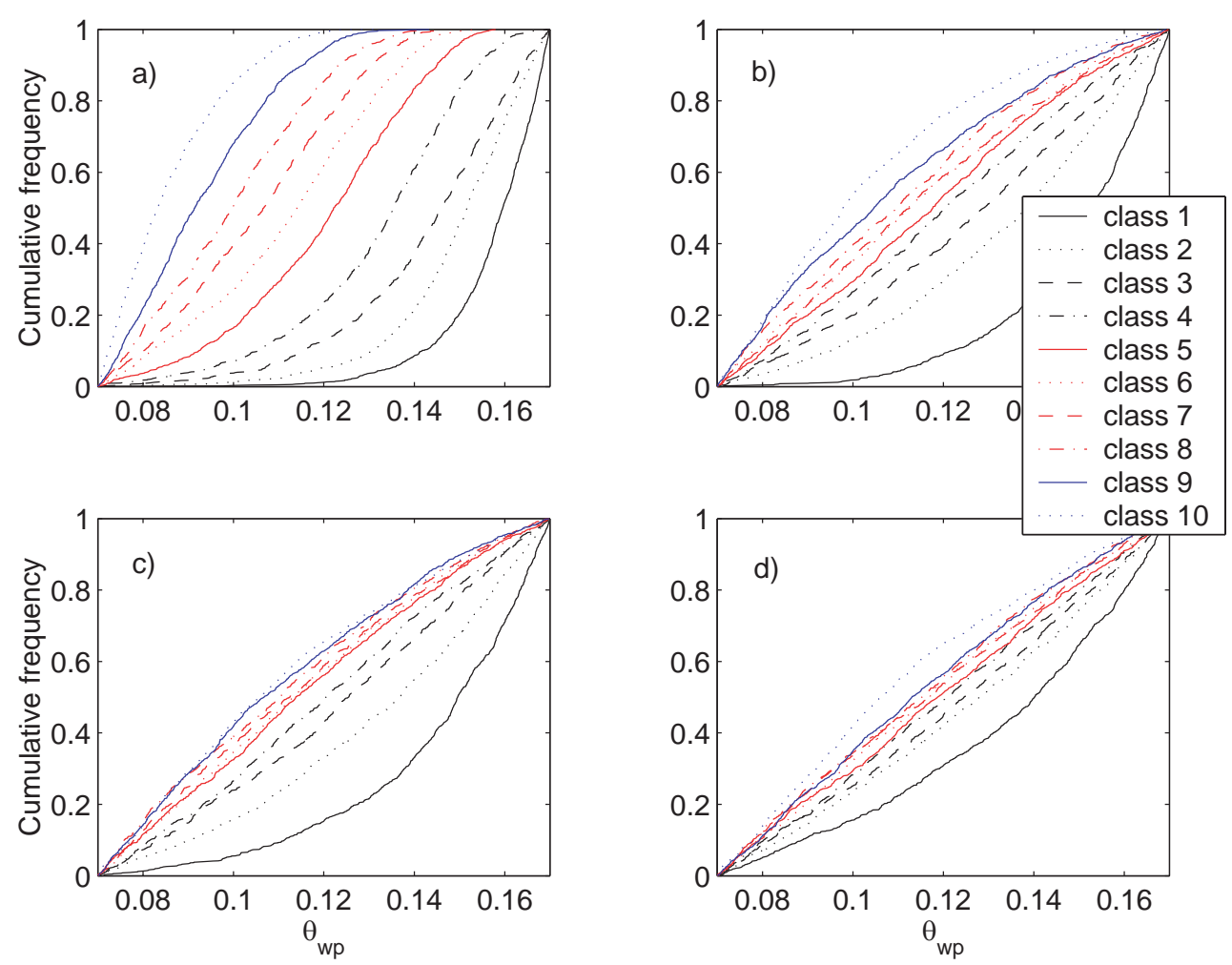

Fig. 7. The $\theta_{\mathrm{wp}}$ cumulative frequency of the 10 performance classes for: (a) sub-period 1, (b) sub-period 2, (c) sub-period 3, (d) sub-period 4. 

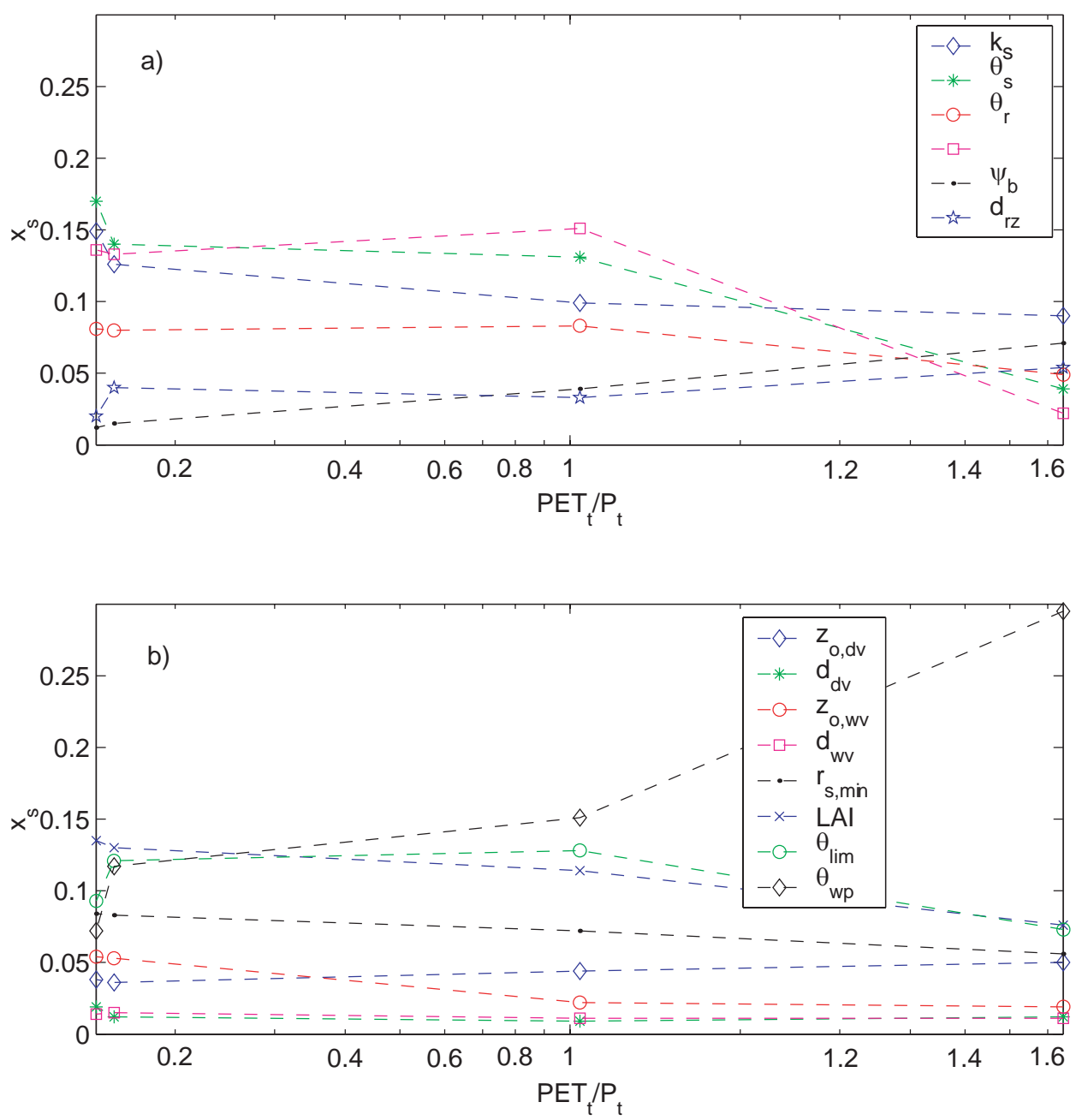

Fig. 8. The sensitivity indexes ( $x_{s}$ ) of the: (a) soil parameters, and (b) vegetation parameters plotted against PET/P ${ }_{t}$

which the drainage become relatively less important. However, note that the evapotranspiration is always sensitive to $k_{s}$, also for the dry sub-period (but with lower values, equal to 0.092), because, at the Pieve Vergonte site, the conditions never become so dry as to render drainage negligible.

The evapotranspiration sensitivity to $\psi_{b}$ is generally low but increases in the dry sub-period. Indeed, from the soil water retention curve Eqn. (1), when the soil is dry, the soil water potential is high and changes of $\psi_{b}$ in Eqn. (1) affect soil water content more, i.e. ET.

The ET sensitivity to $d_{r z}$ is low and increases slightly for the dry sub-period ( $\left.x_{s}=0.054\right)$, as suggested by Eqn. (3).

With regard to vegetation parameters, ET sensitivity is high for some parameters and negligible for others (Fig. 8(b)). $\theta_{w p}$ affects significantly ET modelling as already observed in Fig. 7. For the dry sub-period the sensitivity index of $\theta_{w p}$ reaches the highest value (0.3) of all the parameters. This result is significant, confirming the importance of a correct representation of vegetative properties which, under water-limited conditions, control the evapotranspiration process. Note that in conditions wetter than those reached in the 287-314 sub-period, the sensitivity to $\theta_{w p}$ should become negligible; in the event, however, the observation period did not reach such wet states. Indeed, in an absolute sense, the sub-period was not particularly wet and $\bar{\theta}_{r z}$ remains at values equal to 0.26 , well removed from saturated conditions (Table 2).

Instead, $\theta$ impacts differently on ET modelling. Its sensitivity index is small for the dry sub-period (which is at first counter-intuitive), increases for wetter sub-periods, and finally decreases again for the wettest sub-period. Indeed, for the second sub-period (intermediate hydrometeorological conditions), the simulated soil moisture range is less or equal to $\theta_{\text {lim }}$ which influences $E T$ significantly (see Eqn. (8)). Instead, in the dry sub-period the $\theta_{l}$ values 
are closer to the wilting point, and the sensitivity index of $\theta_{\text {lim }}$ decreases, as ET is vanishingly small for any value of $\theta_{\text {lim }}$. Finally, in the wettest sub-periods (3 and 4) ET is closer to the potential rate (atmospheric controlled) and, hence, is not influenced by $\theta_{\text {lim }}$.

The $L A I$ and $r_{s, \text { min }}$ are relatively important in ET modelling. The sensitivity of $E T$ to $L A I$ is relatively high for the wettest sub-period $(=0.135)$, because ET is more atmosphere controlled, and reaches the potential rate estimated through Eqn. (6). Moreover, LAI is a parameter of the interception storage, and also affects ET computation through the interception process, which becomes more important for wet periods. The sensitivity index of $r_{s, \min }$ is also high for wet sub-periods, because of Eqn. (6).

Finally, precision in the other vegetation parameters is less important for ET predictions. Only the sensitivity indices of $z_{o, d v}$ and $z_{o, w v}$ increase (about 0.05 , which is low compared to the other sensitivity indices) in dry and wet sub-periods respectively.

\section{Conclusions}

Recent developments have made LSMs more complex by inclusion of more processes and controlling variables, increasing parameter number and uncertainty in their estimates. To overcome these uncertainties, prior to applying a distributed LSM over the whole Toce basin, located in the Italian Alps, a field campaign was conducted at an experimental plot within the basin, and then the skill and parameter importance (sensitivity) was explored in an existing LSM, the TOPLATS model of Famiglietti and Wood (1994).

In the summer and autumn of 1999, a time frame that included both wet (atmosphere controlled) and dry (soil controlled) periods, actual evapotranspiration estimates were derived using the Bowen ratio method and, for a short period, the eddy correlation method; both methods were in good agreement. This result demonstrates the accuracy and reliability of micrometeorological measurements for land surface water vapor flux estimates in Alpine basins.

The calibrated LSM predicts actual evapotranspiration quite well over the whole observation period, suggesting that this LSM is acceptable for a spatially distributed application for basin-scale land surface flux predictions in the Toce basin.

Using the global multivariate technique, a sensitivity analysis of the evapotranspiration to model parameters was performed separately in wet and dry periods of the campaign. The global analysis of the sensitivity of the ET model to the parameters, conditioned on background hydrometeorological conditions, demonstrated that:
(1) the evapotranspiration is highly sensitive to all the soil parameters, except the air entry suction head. The evapotranspiration sensitivity index for $k_{s}, \theta_{s}$ and $B$ was more important during wet periods, when changes in these parameters induce notable changes in the drainage rates and thus influences the moisture status of the soil strongly.

(2) The highest overall sensitivity is for $\theta_{w p}$, with the greatest sensitivity being for the dry period. The other vegetation parameters $\left(\theta_{\text {lim }}, L A I\right.$ and $\left.r_{s, \text { min }}\right)$ were also important, with sensitivity to LAI exceeding that of other variables in the wettest conditions.

(3) Aerodynamic parameters $\left(z_{o, d v}, z_{o, w v}, d_{d, v}\right.$ and $\left.d_{w, v}\right)$ were less critical to the ET predictions in the context of this LSM format under the prevailing hydro-meteorological conditions.

The sensitivity to $\theta_{w p}$ during the dry periods underlies the importance of accurate specification of vegetation properties, even in a typically humid Alpine basin such as the Toce, if reasonable hydroloigcal predictive skill is to be achieved. However, the results suggest that the TOPLATS model does not require any major effort in estimating the aerodynamic properties of the landscape for future distributed applications of this model in the context of RAPHAEL.

\section{Acknowledgments}

This research project is part of the TOCEX: the TOCe valley Experiments, MAPSOP Hydrological Experiments. This research was funded by Gruppo Nazionale per la Difesa delle Catastrofi Idrologiche, of National Research Council of Italy through grant \#01.01072.PF42, and the Ministero dell'Università e della Ricerca Scientifica e tecnologica (MURST) of Italy through grant \#MM08103322_004. The Laboratory of Hydrology and Water Management of the University of Gent is acknowledged for providing most of the experiment instruments. J. S. Famiglietti and E. F. Wood are also thanked for providing the TOPLATS model.

\section{References}

Albertson, J.D., and Kiely, G., 2001. On the structure of soil moisture time series in the context of Land Surface Models. $J$. Hydrol., 243, 101-119.

Bashford K.E., Beven K.J. and Young P.C., 2002. Observational data and scale-dependent parameterizations: explorations using a virtual hydrological reality. Hydrol. Process., 16, 293-312.

Beven, K., 1995. Linking parameters across scales-subgrid parameterizations and scale-dependent hydrological models. Hydrol. Process., 9, 507-525. 
Brooks, R.H. and Corey, T., 1964. Hydraulic properties of porous media. Hydrology Paper No. 3, Colorado State Univ., Ft. Collins, Colorado, USA.

Brubaker, K.L. and Entekhabi, D., 1995. An analytic approach to modeling land-atmosphere interaction 1. Construct and equilibrium behavior. Water Resour. Res., 31, 619-632.

Brutsaert, W., 1982. Evaporation into the Atmosphere. Kluwer, Dordrecht, The Netherlands. 299pp.

Cayrol, P., Kergoat, L., Moulin, S., Dedieu, G. and Chehbouni, A., 2000. Calibrating a coupled SVAT-vegetation growth model with remotely sensed reflectance and surface temperature - A case study for the HAPEX-Sahel, grassland sites. J. Appl. Meteorol., 39, 2452-2472.

Endreny, T.A., Wood, E.F. and Lettenmaier, D.P., 2000. Satellitederived digital elevation model accuracy: hydrological modelling requirements. Hydrol. Process., 14, 177-194.

Famiglietti, J.S., and Wood, E.F., 1994. Multiscale modelling of spatially variable water and energy balance processes Water Resour. Res., 30, 3061-3078.

Finch, J.W., 1998. Estimating direct groundwater recharge using a simple water balance model - sensitivity to land surface parameters. J. Hydrol., 211, 112-125.

Franks, S.W., Beven, K.J., Quinn, P.F. and Wright, I.R., 1997. On the sensitivity of soil vegetation atmosphere transfer (SVAT) schemes: Equifinality and the problem of robust calibration. Agric. For. Meteorol., 86, 63-75.

Giorgi, F. and Avissar, R.,1997. Representation of heterogeneity effects in earth system modeling: experience from land surface modeling. Rev. Geophys., 35, 413-438.

Halldin, S., Gryningb, S-E., Gottschalkc, L., Jochumd, A., Lundina, L-C. and Van de Griend, A.A., 1999. Energy, water and carbon exchange in a boreal forest landscape - NOPEX experiences. Agric. Forest. Meteorol., 98-9, 5-29.

Henderson-Sellers, A., Yang, Z. and Dickinson, R.E., 1993. The Project for Intercompararison of Land surface Parameterization Schemes. Bull. Amer. Meteorolog. Soc., 74, 1335-1349.

Houser, P., Shuttleworth, W., Famiglietti, J., Gupta, H.,Syed, K. and Goodrich, D., 1998. Integration of soil moisture remote sensing and hydrological modeling using data assimilation. Water Resour. Res., 34, 3405-3420.

$\mathrm{Hu}, \mathrm{Z}$. and Islam, S., 1996. A method to evaluate the importance of interactions between land surface and atmosphere. Water Resour. Res., 32, 2497-2505.

Jackson, T., 1997. Experiment plan: Southern Great Plains 1997 (SGP97) Hydrology Experiment. USDA-ARS Hydrology Laboratory, Beltsville, MD.

Koster, R.D. and Milly, P.C.D., 1997. The interplay between transpiration and runoff formulations in land surface schemes used with atmospheric models. J. Climate, 10, 1578-1591.

Kutílek, M. and Nielsen, D.R., 1994. Soil Hydrology. Catena, Germany. 370pp.

Lai, C.-T. and Katul, G., 2000. The dynamic role of root-water uptake in coupling potential to actual transpiration. $A d v$. Water Resour., 23, 427-439.
Milly, P.C.D., 1986. An event-based simulation model of moisture and energy fluxes at a bare soil surface. Water Resour. Res., 22, $1680-1692$

Montaldo, N. and Albertson, J.D., 2001. On The Use Of The Force-Restore SVAT Model Formulation For Stratified Soils. J. Hydrometeorol., 2 , 571-578.

Montaldo, N., Toninelli, V., Mancini, M., Albertson, J.D., Troch, P.A. and Rosso, R., 2001. Estimation of actual evapotranspiration and Soil Moisture in the Pieve Vergonte case study. Technical Report n. 10, University of Brescia, Italy.

Nash, J.E. and Sutcliffe, J.V., 1970. River flow forecasting through the conceptual models, Part 1: A discussion of principles. $J$. Hydrol., 282-290.

Noihlan, J. and Planton, S., 1989. A Simple parameterization of Land Surface Processes for Meteorological Models. Mon. Weather Rev., 117, 536-549.

Pauwels, V.R.N., Hoeben, R., Verhoest, N.E.C., De Troch, F.P. and Troch, P.A., 2002. Improvement of TOPLATS-based discharge predictions through assimilation of ERSbased remotely sensed soil moisture values. Hydrol. Process., 16, 9951013.

Philip, J.R., 1957. The theory of infiltration : 1. The infiltration equation and its solution. Soil Sci., 83, 345-357.

Pitman, A.J. et al., 1999. Key results and implications from phase 1(c) of the Project for Intercomparison of Land-Surface Parametrization Schemes. Clim. Dynam., 15, 673-684.

Rawls, W.J., Brakensiek, D.L. and Saxton, K.E., 1982. Estimation of Soil Water Properties. Trans. ASAE, 25, 1316-1320.

Reynolds, W. D. and Elrick, D.E., 1985. In situ measurement of field-saturated hydraulic conductivity, sorptivity, and the $\alpha$ parameter using the Guelph permeameter. Soil Sci., 140, 292302.

Reynolds, W.D., Elrick, D.E. and Clothier, B.E., 1985. The constant head well permeameter: effect of unsaturated flow. Soil Sci., 139, 172-180.

Rosso, R., 1994. An introduction to spatially distributed modeling of basin response. In: Advances in Distributed Hydrology, R. Rosso, I. Becchi, A. Bemporad and A. Peano (Eds.), Water Resources Publications, Highlands Ranch, Colorado, USA. 330.

Spear, R.C. and Hornberger, G.M., 1980. Eutrophication in Peel Inlet - II. Identification of critical uncertainties via Generalised Sensitivity analysis. Water Resour., 14, 43-49.

Spear, R.C., Grieb, T.M. and Shang, N., 1994. Parameter uncertainty and interaction in complex environmental models. Water Resour. Res., 30, 3159-3169.

Wigmosta, M.S., Vail, L.V. and Lettenmaier, D.P., 1994. A distributed hydrology-vegetation model for complex terrain. Water Resour. Res., 30, 1665-1679. 